\title{
Resultados da Rodada Uruguai: uma tentativa de síntese
}

\author{
LUIZ FELIPE PALMEIRA LAMPREIA
}

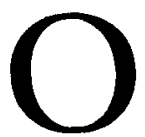

MAIOR ACORDO comercial da História se constitui de uma Ata Final que incorpora os resultados da Rodada Uruguai de Negociaçóes Comerciais Multilaterais e da qual fazem parte integrante listas nacionais em que se registram obrigações contratuais de redução ou eliminação de tarifas específicas e de barreiras não tarifárias ao comércio de bens, e compromissos iniciais de liberalização do comércio de serviços.

O conjunto de textos de instrumentos legais negociados desde o lançamento da Rodada, em setembro de 1986, apresenta-se na Ata Final sob a forma de anexos ao Acordo que cria a Organização Mundial de Comércio (WTO), que não fora prevista em Punta del Este, mas cuja constituição foi julgada necessária para fins de abrigar, dentro de uma única moldura institucional: o Acordo Geral sobre Tarifas e Comércio, tal como modificado pela Rodada Uruguai (Gatt); todos os acordos e arranjos concluídos desde 1947 sob os auspícios do mesmo Gatt; e os resultados completos da recém-concluída Rodada. Seria, nesse sentido, incorreto afirmar que a WTO substitui o Gatt, já que, em primeiro lugar, a organização não se confunde com os textos legais anexos ao seu convênio constitutivo, e, em segundo, porque o Gatt continua a existir, acrescido' de sete textos de entendimento (understanding) sobre diferentes dispositivos do Acordo Geral e do Protocolo de Marraqueche, que estabelece as diretrizes para cumprimento das obrigaçốes assumidas através das anexas listas nacionais e de concessóes tarifárias e nãotarifárias em matéria de bens. Com esses acréscimos - e mais os que foram feitos ao longo de sete rodadas de negociações, especialmente a Rodada Tóquio, concluída em 1979 -, o Acordo Geral passa a ser denominado Gatt 1994.

Além do Gatt94, o pacote de acordos multilaterais relativos ao comércio de bens inclui ainda doze textos, cobrindo os seguintes temas: agricultura; aplicação de medidas sanitárias e fitossanitárias; têxteis e confecçôes; barreiras técnicas ao comércio; medidas de investimento relacionadas ao comércio; implementação do Artigo VI do Gatt; implementação do Artigo VII do Gatt; inspeção de préembarque; regras de origem; procedimentos relativos a licenças de importação; subsídios e medidas compensatórias; e salvaguardas. 
No que diz respeito a serviços, o acordo alcançado na Rodada compreende três elementos: Acordo Geral sobre o Comércio de Serviços (Gats), acordo-quadro, cujas obrigaçóes básicas se aplicam a todos os países membros; anexos referentes a situações especiais em setores específicos (movimento de mão-de-obra, serviços financeiros, telecomunicações, transportes aéreos); e listas nacionais de compromissos de liberalização (vide parágrafo inicial), que poderão ser ampliados pela via da negociação.

O Acordo sobre Aspectos dos Direitos de Propriedade Intelectual Relacionados ao Comércio (Trips) é a terceira parte do tripé sobre o qual se assenta a WTO no que diz respeito à sua base normativa. $O$ Acordo de Trips dispóe sobre a aplicabilidade dos princípios básicos do Gatt e dos acordos internacionais sobre propriedade intelectual; estipula os direitos de propriedade intelectual considerados adequados; determina medidas consideradas eficazes para fazer cumprir aqueles direitos; prevê mecanismos para a solução multilateral de controvérsias; e contém disposições transitórias, especialmente com relação à data de implementação do acordo.

O segundo documento anexo ao Acordo que constitui a WTO é o Conjunto de Regras e Procedimentos Relativos à Solução de Controvérsias (Understanding on Rules and Procedures Governing the Settlement of Disputes (DSU), estágio mais acabado de um sistema tido como uma das pedras fundamentais da ordem comercial multilateral. A aplicação do DSU deverá fortalecer substancialmente o sistema já existente, estendendo a maior automaticidade acordada já por ocasião da reunião ministerial de 1986 à adoção das conclusões dos panels bem como de um recém-criado órgão de apelação.

O Mecanismo de Exame de Políticas Comerciais (Trade Policy Review Mechanism ou Tprm) é o terceiro documento anexo ao acordo constitutivo da WTO. Seu funcionamento propicia análise e avaliação completas das políticas e práticas comerciais de cada um dos membros da organização, permitindo que seja determinado o impacto dessas políticas e práticas sobre o sistema multilateral de comércio.

O quarto e último anexo compóem-se de quatro acordos comerciais plurilaterais que emanaram da Rodada Tóquio e cujos dispositivos continuam sendo obrigatórios apenas para os membros que indicaram sua disposiçáo de aceitá-los. Trata-se do Acordo sobre Comércio de Aeronaves Civis, do Acordo sobre Compras Governamentais, do Acordo Internacional sobre Produtos Lácteos, e do Acordo Internacional sobre Carne Bovina, sendo este o único desses quatro instrumentos do qual o Brasil é parte. 
Caberia mencionar ainda, para concluir esta parte introdutória, que os ministros reunidos em Marraqueche entre 12 e 15 de abril último para a derradeira sessáo do Comitê de Negociações Comerciais da Rodada Uruguai aprovaram igualmente uma série de decisóes e declaraçóes que complementam os acordos concluídos em cumprimento ao mandato de Punta del Este ou conformam o programa de trabalho concebido para implementar os resultados da Rodada. Neste segundo grupo incluem-se a Decisão sobre o Estabelecimento de um Comitê Preparatório para a WTO e a Decisão sobre o Comércio e Meio Ambiente, tema que não fora incluído na agenda de Punta del Este, mas que os participantes da Rodada houveram por bem submeter à discussão no âmbito de um comitê a ser criado pela WTO.

\section{Acordo Constitutivo da Organização Mundial de Comércio (WTO)}

O acordo que cria a WTO prevê uma estrutura encabeçada por uma Conferência Ministerial a realizar-se uma vez a cada dois anos. $O$ órgão incumbido de supervisionar a operação do Acordo e das decisões ministeriais é o Conselho Geral, que se reunirá com maior frequiência, em intervalos regulares. Também ao Conselho Geral cumprirá o exercício das funçōes de Órgão de Solução de Controvérsias e de Mecanismo de Exame das Políticas Comerciais, além da tarefa de criação de órgãos subsidiários, tais como um Conselho de Bens, um Conselho de Serviços e um Conselho de Trips. Caber-lhe-á, finalmente, monitorar os quatro arranjos plurilaterais que emanaram da Rodada Tóquio e que não foram objeto de negociação global na Rodada Uruguai. O quadro jurídico da WTO garante a aplicação do método de aceitação indivisa dos compromissos (single undertaking approach) que os Ministros em Punta del Este haviam aprovado com vistas a que nenhum tema da agenda das negociaçóes ficasse excluído do pacote final. Dessa forma, para tornar-se membro da Organização é necessário acolher todos os resultados da Rodada Uruguai, sem exceção.

\section{Gatt 1994}

Diversos artigos do velho Acordo Geral foram objeto de interpretação no âmbito de um grupo negociador específico cujo produto final consistiu num conjunto de sete textos, o qual compóe, juntamente com o texto básico acordado em 1947 (e outros documentos básicos adicionais), o chamado Gatt 1994. Dentre esses understandings caberia destacar os relativos aos Artigos XII e XVIII, que contêm disposições referentes à aplicação de medidas restritivas em caso de desequilíbrio no balanço de pagamentos; Artigo XXIV, que dispõe sobre a formação de uniốes aduaneiras e zonas de livre comércio; Artigo XXV, que trata de dispensa de obrigaçóes (waivers); Artigo XXVIII, que contém disposiçóes sobre 
modificação das listas de concessóes tarifárias; e Artigo XXXV, que dispóe sobre não-aplicaçáo do Acordo Geral.

De acordo com o novo texto interpretativo das disposiçóes que regem o recurso a medidas por motivo de balanço de pagamentos, devem os seus usuários esforçar-se para prejudicar o mínimo possível os fluxos comerciais, dando preferência, nesse sentido, a medidas baseadas em preço, como sobretaxas à importação e depósitos prévios em detrimento de restriçốes quantitativas. Novos procedimentos para consultas no âmbito do Comitê de Balanço de Pagamentos e para notificação de medidas também fazem parte do understanding.

O texto interpretativo do Artigo XXIV visa a esclarecer e reforçar os critérios e procedimentos, para exame de unióes aduaneiras ou áreas de livre comércio recém-criadas ou ampliadas, bem como para avaliação de seus efeitos sobre terceiras partes. Visa também a clarificar o procedimento a ser seguido para fixar qualquer ajuste compensatório que se faça necessário na eventualidade de que membros de uma nova união aduaneira se proponham a elevar tarifas consolidadas.

Procedimentos novos para a concessão de waivers de disciplinas do Acordo Geral e dispositivos destinados a especificar as datas de expiração dos waivers a serem concedidos no futuro, bem como indicar as datas de expiração dos que estáo em vigor, constituem o fulcro do acordo interpretativo do Artigo XXV. Cabe observar, porém, que o próprio Acordo Constitutivo da WTO contém normas relativas à concessão de waivers.

Nos termos do texto interpretativo do Artigo XXVIII, é reconhecido direito de negociador em processos relativos ao pagamento de compensação por modificação ou suspensão de concessóes tarifárias também às partes responsáveis pela mais alta proporção das exportações do produto afetado. Esse procedimento habilita países menores e certamente alguns países em desenvolvimento a participar das negociaçóes sob o Artigo XXVIII e obter satisfação pelos prejuízos reais ou potenciais causados.

Com a entrada em vigor da WTO pode qualquer um dos seus membros invocar as disposiçóes do Gatt relativas à não-aplicação do Acordo Geral a outros membros, mesmo depois de haver iniciado negociações tarifárias bilaterais. A norma segundo a qual qualquer invocação daquelas disposições deve estender-se a todos os acordos multilaterais está inclứda no próprio acordo constitutivo da WTO.

\section{Protocolo de Marraqueche/acesso a mercados}

As listas nacionais anexas ao Protocolo de Marraqueche refletem a complexidade das negociaçóes sobre acesso a mercados em suas duas principais verten- 
tes: concessões tarifárias e não-tarifárias tanto para produtos agrícolas, quanto para produtos industriais. No caso de produtos agrícolas, o objetivo de maior liberalização do comércio é alcançado através não só de rebaixas tarifárias em bases de nação mais favorecida, mas também da abertura de quotas tarifárias. Já a meta de reduzir as distorções sobre o comércio de bens agropecuários se traduz nos compromissos de limitação, tanto dos subsídios à exportação quanto do apoio interno.

Consolidações ou reduções tarifárias para produtos industriais acordadas no âmbito da Rodada deverão ser implementadas em cinco cortes iguais, sendo que o primeiro será efetuado na data de entrada em vigor do acordo constitutivo da WTO e os demais no dia primeiro de janeiro dos anos seguintes. No caso dos produtos agrícolas, vale o cronograma de reduções enunciado nas respectivas listas nacionais.

Em vista da implementação do programa de liberalização do comércio exterior do Brasil, nossa oferta em matéria de acesso a mercados não representa sacrificios adicionais, à medida em que não implica cortes nas tarifas em vigor e permite manter margens de flexibilidade suficientemente distantes das tarifas atuais ou da tarifa externa comum para o Mercosul. Pode-se afirmar, adicionalmente, que o Brasil teria adquirido, apenas com as medidas que tomou autonomamente no curso dos últimos anos, algumas vantagens importantes, tais como: reduções gerais (38\% em termos de média ponderada) nas tarifas hoje vigentes nos países desenvolvidos e, por conseguinte, melhoria real nas condiçóes de acesso para produtos de nosso interesse; eliminação tarifária, ou reduções substanciais, em setores objeto de acordo entre os principais parceiros (papel, brinquedos, equipamento científico entre outros, que foram incluídos nos resultados do encontro de Tóquio); redução das tarifas máximas para produtos têxteis nos EUA, segundo sua proposta de harmonização, passando o subsetor mais protegido - o de confecções - a apresentar um teto de $32 \%$; e redução significativa das alíquotas para produtos tropicais ou industrializados nos principais mercados importadores (cortes de $40 \%$ na CEE e nos EUA e de $89 \%$ no Japão).

\section{Acordo sobre Agricultura}

As concessões e compromissos mencionados derivam do Acordo sobre Agricultura, marco jurídico-institucional para o projeto de reforma de longo prazo do comércio agrícola e das políticas internas que se deseja levar a cabo nos próximos anos. Um dos seus principais traços distintivos é o instituto da tarifação, pelo qual todas as medidas não-tarifárias aplicadas na fronteira são substituídas por tarifas. Aos indices de proteçấo resultantes do processo - assim como a outras tarifas incidentes sobre produtos agrícolas - deve ser aplicado um redutor da ordem de $36 \%$ no caso de países desenvolvidos e de $24 \%$ no caso de países em desenvolvimento, com a exigência de reduçóes mínimas para cada linha tarifária. 
No que se refere aos compromissos de redução de subsídios à exportação, prevaleceram os níveis que os dois principais parceiros comerciais - CEE e EUA - acordaram bilateralmente, no Blair House Agreement original (36\% abaixo do nível do período de referência - 1986 a 1990 - ao longo dos seis anos de implementação, $21 \%$ em quantidade no mesmo período). Flexibilizaram-se, por outro lado, as condiçôes para sua aplicação com o aumento das quantidades a partir das quais começam a incidir as reduçóes. Estudo realizado por Patrick Messerlin mostra, em termos estatísticos, o impacto das reduçóes previstas em Blair House e das finalmente aceitas em Marraqueche, alertando para o aspecto da falta de ganhos para o consumidor na forma de maiores quantidades subsidiadas de produtos como carne bovina, carne de frango, queijo, trigo e farinha de trigo.

Também sofreu modificação, na fase derradeira das negociações, a chamada cláusula de paz, em cujos termos, certas medidas previstas no Acordo sobre Subsídios não serão aplicadas com respeito a políticas caracterizadas como de green box (apoio governamental nas áreas de pesquisa, controle de doenças, infraestrutura e segurança alimentar) bem como de subsídios à produção e à exportação mantidos em conformidade com os compromissos pactuados. Nesse mesmo contexto, a invocação dos dispositivos relativos à aplicação de direitos compensatórios só se fará em casos imperativos, exercendo-se normalmente a autocontenção (due restraint). A peace clause vigorará por um período de nove anos e não mais seis, como previsto inicialmente.

A despeito das limitaçóes para a negociaçăo do texto final do pacote agrícola, o acordo final oferece aspectos positivos, inclusive da perspectiva de países em desenvolvimento, beneficiados com o respeito ao princípio do tratamento especial e diferenciado, sobretudo no que tange à aplicação dos compromissos de redução tanto das tarifas quanto dos subsídios. Ademais, a mera aplicação linear dos compromissos acordados beneficia, em maior ou menor medida, as exportaçóes brasileiras, inclusive de suco de laranja congelado, cuja tarifa, por se tratar de produto considerado sensivel, sofreu redução de $20 \%$ na UE e $15 \%$ nos EUA.

Paralelamente ao Acordo sobre Agricultura, emergiu da Rodada um Acordo sobre Medidas Sanitárias e Fitossanitárias (SPS), que tem o objetivo de disciplinar o uso de regulamentos relativos à segurança dos alimentos e à sanidade animal e vegetal. Ao reconhecer o direito que têm os governos de tomar medidas sanitárias e fitossanitárias, o acordo restringe a aplicação dessas medidas aos casos em que seja necessário proteger a vida ou a saúde dos seres humanos, dos animais ou das plantas, vedando-se qualquer arbitrariedade ou discriminação entre membros. A simples existência de um Acordo sobre SPS complementa os esforços realizados pelos integrantes do Grupo de Cairns, entre os quais o Brasil, no sentido de obter regras mais claras e específicas dentro do Gatt para a imposição de medidas que possam constituir obstáculo ao comércio de produtos agrícolas. 


\section{Acordo sobre Têxteis e Confecções}

Embora considerado insatisfatório pelos principais exportadores, o Acordo sobre Têxteis e Confecçóes representa o cumprimento do mandato que fora fixado pelos signatários da Declaração de Punta del Este, qual seja, o de propiciar a eventual integração do setor no Gatt, com base em regras e disciplinas fortalecidas. Como a maior parte do comércio de têxteis e confecções está sujeito a quotas bilaterais negociadas ao amparo do Acordo Multifibras (AMF), tratou-se de definir as modalidades de phasing out do AMF, que deverá completar-se até o ano 2005 na presunção de que o WTO entre em vigor em 1995.

O Acordo prevê a criação de um mecanismo de salvaguardas transitórias que poderá ser utilizado com relação a produtos ainda não-integrados em qualquer etapa, e inclui dispositivos capazes de lidar com problemas de fraude aos compromissos acordados através de transbordo, declaraçóes falsas acerca do território de origem, contrafação de documentos oficiais etc. Para supervisionar a implementação dos compromissos será estabelecido um órgão de monitoramento que, de certa forma, substitui o Órgão de Vigilância constituído em decorrência do AMF, e ao qual caberá em especial examinar açóes unilaterais tomadas ao amparo do mecanismo de salvaguardas.

Pode-se dizer que, em suas linhas gerais, o Acordo protege os interesses da indústria nacional de têxteis e confecçóes, e oferece elementos que lhe permitem, em caso de necessidade, defender-se contra prejuízos causados pelo aumento súbito e substancial de importaçóes de produtos concorrentes. Aponta, ao mesmo tempo, para o dever imperativo de efetuar os ajustes que habilitem o setor a enfrentar a competição externa dentro dos próximos dez anos, isto é, ao longo do período de integração multilateralmente acordado.

\section{Acordo sobre Medidas de Investimento relacionadas ao Comércio}

O Acordo sobre Trims representa o reconhecimento de que certas medidas de investimento, ao contrariar o que dispóem os Artigos III (tratamento nacional) e XI (proibição de restriçóes quantitativas) limitam e distorcem o comércio, e, por conseguinte, não devem ser aplicadas. Uma lista ilustrativa de Trims julgadas incompatíveis com os mencionados artigos está apensa ao acordo e inclui exigências de conteúdo local e de trade balancing. As medidas em vigor nos países desenvolvidos devem ser derrogadas dentro do prazo de dois anos, devendo os países em desenvolvimento eliminar as suas num período de cinco anos.

Considerando os objetivos que levaram os EUA a inserir o tema nas negociaçóes, os resultados alcançados aqui foram bastante modestos. Conforme acor- 
dado em Punta del Este, os esforços tiveram que se restringir a Trims relacionadas apenas ao comércio de bens, não havendo penetrado a seara do estabelecimento e dos investimentos de companhias no exterior. $\mathrm{O}$ acordo tampouco trata de exigências de desempenho exportador (export performance requirements), medidas que são examinadas em função de seu vínculo com subsídios no contexto do Acordo sobre Subsídios e Medidas Compensatórias.

\section{Acordo sobre a Implementação do Artigo VI do Acordo Geral (Antidumping)}

Negociou-se na Rodada Uruguai a terceira versão de um acordo interpretativo do Artigo VI do Acordo Geral, a primeira tendo resultado da Rodada Kennedy e a segunda da Rodada Tóquio. Como nos casos anteriores, seu objetivo é dotar o sistema de regras mais precisas e mais claras para a aplicação dos possíveis remédios contra as importações de um produto cujo preço de exportação esteja abaixo do seu valor normal, causando por isso prejuízo material a uma indústria no território do país importador.

Tais regras referem-se à metodologia que pode ser utilizada para determinar se um produto está sendo dumped; aos critérios a serem levados em conta numa determinação de dano; aos procedimentos a serem seguidos na abertura $\mathrm{e}$ condução de investigações antidumping; à implementação e duração de medidas antidumping. Um dispositivo novo no acordo exige o encerramento imediato de investigação em casos nos quais as autoridades hajam determinado que a margem de dumping é de minimis ou que o volume das importaçóes dumped é negligenciável. Outra novidade consiste na obrigação de suspender todas as medidas antidumping cinco anos após a data em que tiverem sido impostas, a menos que haja uma decisão pela qual, na hipótese de suspensão da medida, provavelmente dumping e dano continuariam ou voltariam a ocorrer.

No último mês das negociações a delegação norte-americana propôs nada menos de onze emendas ao texto constante do Projeto de Ata Final apresentado pelo ex-diretor geral - Arthur Dunkel -, em dezembro de 1991, cujo conteúdo todas as demais delegaçôes não tinham dificuldades insuperáveis em aceitar. Diante da forte oposição, sobretudo por parte de representantes de países afetados por abusos na aplicação da lei de comércio dos EUA, entre os quais o Brasil, foram consideravelmente limitadas as alteraçóes propostas. Ainda assim, de acordo com o que finalmente se acordou, os tradicionais usuários de medidas antidumping poderão beneficiar-se da norma segundo a qual as determinações factuais feitas pelas autoridades investigadoras nacionais não poderão ser derrubadas (por um panel da WTO) caso o estabelecimento dos fatos tenha sido apropriado e a avaliação dos fatos, objetiva e não-tendenciosa (unbiased). 
Para o Brasil, cujos setores produtivos acham-se hoje muito mais expostos à concorrência internacional do que quando se iniciou a Rodada, o acordo poderá constituir opção para defesa contra práticas desleais, desde que disponha de recursos materiais e humanos para a instalação e o adequado funcionamento de um sistema de investigaçáo e aplicação de medidas. Outra condição fundamental é fortalecer esse sistema de forma a resistir a pressóes políticas que levem a processos mal instruídos e, portanto, passíveis de serem revertidos até mesmo por panels mais limitados em sua esfera de atuação.

\section{Acordo sobre Salvaguardas}

A importância do Acordo sobre Salvaguardas, que expande e clarifica as disposições do Artigo XIX do Acordo Geral, está, de um lado, na proibição das chamadas medidas de zona cinzenta e, de outro, na adoção de uma sunset clause para todas as açóes destinadas a proteger indústrias específicas contra aumentos súbitos e imprevistos de importações que estejam causando ou ameaçando causar danos a essas indústrias.

Restrições voluntárias à exportação, acordos de organização de mercados e quejandos são doravante ilegais, sendo que as medidas existentes terão que conformar-se ao acordo ou ser gradualmente eliminadas dentro de quatro anos, a partir da entrada em vigor do acordo constitutivo da WTO. Quanto às medidas tomadas ao amparo do Artigo XIX, terão elas que ser suspensas dentro do período máximo de oito anos a partir da data de sua imposição, ou dentro do período de cinco anos, a partir da entrada em vigor do acordo que cria a WTO.

A matéria de maior controvérsia nas negociaçóes em torno do Acordo sobre Salvaguardas foi a da seletividade, entendendo-se por tal a antiga tese comunitária de aplicação de medidas de forma discriminatória entre supridores do produto sujeito à salvaguarda. Dada a forte reaçáo contrária de países como Japão, Índia, Brasil, Austrália, entre outros, durante todo o processos negociador, só restou das propostas da CEE a possibilidade, descrita no parágrafo 9(b), de o país importador, havendo optado pela imposição de quotas como medida de salvaguarda, afastar-se do princípio de que as restriçóes impostas serão proporcionais à quantidade ou ao valor total do produto importado ao longo de um período representativo anterior. Para tanto, porém, terá de demonstrar, em consultas realizadas sob a égide de um Comitê de Salvaguardas, que as importaçóes dos parceiros discrimináveis cresceram desproporcionalmente com relação ao aumento total e que o afastamento do princípio basilar da náo-discriminação se justifica e é equitativo para todos os supridores. 


\section{Acordo Geral sobre Comércio de Serviços}

As negociações sobre o comércio de serviços na Rodada Uruguai resultaram num conjunto de três grandes vetores, a saber: um acordo-quadro com obrigaçóes básicas aplicáveis a todos os membros; um número de anexos relativos a situaçóes especiais de setores de serviços individualmente considerados; e um conjunto de listas nacionais de compromissos iniciais de liberalização assumidos pelas diferentes partes e passíveis de ampliação no futuro.

Tal como o Acordo Geral sobre Tarifas e Comércio (Gatt), o Gats (Acordo Geral sobre Comércio de Serviços) contém uma cláusula de nação mais favorecida. Prevê, ao mesmo tempo, a possibilidade de que sejam indicadas isençóes específicas para certas atividades em condições que são estipuladas anexas. Também toma emprestadas ao Gatt (Artigo XXIV) as disposições relativas à integração econômica, exceções de caráter geral e exceçóes por motivo de segurança, estas contempladas respectivamente nos Artigos XX e XXI do Gatt.

As disposiçóes sobre acesso a mercados e tratamento nacional, objeto da Parte III do Acordo, suplementam os compromissos assumidos pela via das listas nacionais, ficando claro que "cada membro concederá aos serviços e aos supridores de serviços dos demais membros tratamento não menos favorável que o que for acordado nos termos, limitaçóes e condiçóes pactuadas e descritas em sua lista". É ressaltada, igualmente, a obrigação geral de tratamento igualitário aos supridores estrangeiros e aos supridores domésticos de serviços, obrigaçáo essa que pode ser dispensada desde que, como resultado da diferença de tratamento, não se modifiquem as condições de competição em favor dos supridores nacionais.

Os anexos ao Gatt referem-se a movimento de mão-de-obra; serviços financeiros (sobretudo bancos e seguros); telecomunicaçóes; serviços de transporte aéreo; telecomunicações básicas; e serviços marítimos. Em face das inúmeras dificuldades encontradas na negociação desses anexos, foi decidida, nos momentos finais do processo concluído em 15 de dezembro de 1993, a criação de grupos setoriais e/ou a prorrogação do prazo para uma definição final sobre as ofertas e derrogaçốes n.m.f. Assim, no caso de movimento de pessoas, acordou-se que, no seio do grupo que foi instalado em 15 de maio e cujos trabalhos devem estar encerrados dentro de um prazo de seis meses após a entrada em vigor da WTO, poderão ser negociados compromissos específicos, sendo, porém, de se prever que, com a preocupação dos países desenvolvidos em torno das questóes de imigração, sejam lentos os progressos nessa área. Para serviços financeiros não foi criado grupo de negociação, mas adiada a data para confirmação final dos com- 
promissos iniciais ou das derrogações n.m.f. para seis meses após a entrada em vigor do acordo constitutivo da WTO. Quanto a transportes marítimos, o que se acordou, além da criação de grupo negociador, foi a suspensão das decisões finais sobre ofertas e derrogações até junho de 1996, prazo para encerramento dos trabalhos do grupo.

\section{Acordos sobre Barreiras Técnicas ao Comércio (TBT), Valoração Aduaneira e Licenças para Importação}

Os três acordos constituem versões revistas e ampliadas de três instrumentos negociados na Rodada Tóquio. As principais novidades do acordo sobre TBT em sua mais recente apresentação são as seguintes: a cobertura se estende a métodos de processamento e produção relacionados com as características do próprio produto; os dispositivos de notificação aplicáveis aos governos locais e órgãos governamentais são mais pormenorizados; anexo ao Acordo, passa a existir um Código de Boa Conduta para a Preparação, Adoçáo e Aplicação de Normas Técnicas, aberto à aceitação por entidades especializadas tanto do setor privado quanto do setor público.

O Acordo sobre Implementação do Artigo VII (Valoração Aduaneira) exige que todos os membros da WTO adotem o critério do valor da transação como base para o cálculo dos direitos alfandegários e permite aos serviços de duana solicitar dos importadores informação adicional sempre que tenham motivos para por em dúvida a exatidão do valor declarado dos bens importados. São considerados úteis os dispositivos sobre métodos para valoraçáo de mercadorias para fins de determinação dos direitos alfandegários, mas, dada a controvérsia que cerca os alegados abusos em matéria de transbordo de produtos têxteis e confecções e a generalidade das normas do acordo no que diz respeito à fraude, antecipam-se disputas que talvez só possam ser resolvidas por grupos especiais (panels).

O acordo revisado sobre procedimentos a serem seguidos pelos membros ao conceber licenças para importaçáo visa a aumentar a transparência e a previsibilidade dos sistemas nacionais, obrigando os membros a publicar informação suficiente para que os operadores comerciais tomem conhecimento das bases em que podem ser obtidas as licenças. É importante assinalar que o Brasil não é signatário do atual código de licenças, mas, em decorrência do princípio do single undertaking terá de aceitar as obrigaçóes estipuladas no novo acordo, especialmente no que tange aos critérios de acordo com os quais os procedimentos de licenciamento automático são considerados como não tendo efeitos restritivos sobre o comércio. 


\section{Acordos sobre Regras de Origem e sobre Inspeção Prévia aos Embarques}

O Acordo sobre Regras de Origem não prescreve regras substantivas sobre como determinar o país de origem de uma mercadoria importada, mas limita-se a criar um Comitê no âmbito do Gatt e um Comitê Técnico sob os auspícios do Conselho de Cooperação Aduaneira, em Bruxelas, com a finalidade de executar, dentro de um período de três anos, um programa de harmonização de todas as regras de origem, exceção feita àqueles que dizem respeito à outorga de preferências tarifárias. Até que se finalize esse programa, os membros farão o possível para assegurar, inter alia, que suas regras sejam transparentes, não tenham efeitos restritivos, distorsivos ou desorganizadores sobre o comércio internacional e sejam administradas de maneira consistente, uniforme, imparcial e razoável.

O Acordo sobre Preshipment Inspection confirma que os princípios e obrigaçóes do Gatt se aplicam às atividades das empresas privadas contratadas por governos (geralmente de países em desenvolvimento com infra-estrutura administrativa inadequada) para verificar dados de preço, quantidade e qualidade de mercadorias exportadas, com o objetivo de proteger interesses financeiros nacionais. As negociaçóes sobre o tema terão sido precipitadas por queixas encaminhadas por certos exportadores europeus e norte-americanos que se consideravam prejudicados por práticas abusivas, sobretudo na forma de demandas de informação irrazoáveis, resultando em atrasos nos embarques e, por conseguinte, custos adicionais. Analistas acreditam haver sido logrado aqui um equilíbrio entre as legítimas necessidades tanto dos exportadores quanto dos importadores.

\section{Acordo sobre Subsídios e Medidas Compensatórias}

O Acordo sobre Subsídios e Medidas Compensatórias emanado da Rodada Uruguai compreende vários elementos que não existiam no seu predecessor, 0 Código de Subsídios da Rodada Tóquio, relativo à interpretação e aplicação dos Artigos VI, XVI, XXIII do Gatt. Em primeiro lugar, contém uma definiçâo acordada do que seja subsídio e introduz o conceito de subsídio específico único sujeito às disciplinas do acordo, por ser concedido especificamente a uma empresa ou ramo de produção - ou grupo de empresas ou ramos de produção - dentro da jurisdição da autoridade outorgante.

Também, ao contrário do Código de 1979, estabelecem-se aqui três categorias de subsídio: os proibidos, como os que se concedem em vinculação com o desempenho das exportações; os acionáveis; e os não-acionáveis, a saber, os de aplicação geral e os que envolvem assistência a pesquisa industrial e regiốes desfavorecidas, bem como certos tipos de assistência para adaptar infra-estrutura já existente a novos requisitos ambientais impostos por lei ou regulamentos. 
A parte do acordo que se refere ao uso de medidas compensatórias aplicáveis às importaçóes de produtos subsidiados fixa disciplinas para a abertura de processos, para investigações pelas autoridades nacionais e para a produção de provas de maneira a permitir que todas as partes interessadas possam apresentar informação e expor seus argumentos.

Ao reconhecer que subsídios podem desempenhar papel relevante em programas de desenvolvimento econômico de países em desenvolvimento (e na transição das antigas economias de planejamento central para economias de mercado), o acordo isenta do cumprimento das obrigações relativas a subsídios à exportação, proibidos os países de menor desenvolvimento relativo e os países em desenvolvimento de baixa renda per capita. Outros países em desenvolvimento, como o Brasil, dispóem de oito anos a partir da entrada em vigor do acordo constitutivo da WTO para passar a cumprir aquelas obrigaçóes. Dispóem, ademais, de um período de cinco anos para ajustamento de legislação vigente que pode ser interpretada como exigência de conteúdo local.

\section{Acordo sobre Direitos de Propriedade Intelectual Relacionados ao Comércio}

O Acordo sobre Trips divide-se em três partes, a primeira contendo disposições gerais e princípios básicos, tais como tratamento nacional e uma cláusula de nação mais favorecida; a segunda discorrendo sobre cada um dos direitos, em sucessão (copyright, marcas, apelaçóes geográficas, desenhos industriais, patentes etc.); e a terceira indicando as obrigaçôes dos membros no sentido de estabelecer procedimentos e remédios no contexto de suas legislações nacionais para assegurar que os direitos sejam efetivamente protegidos e respeitados.

Não há dúvida de que o Acordo de Trips representa avanço considerável na consecução do objetivo de proporcionar maior proteção da propriedade intelectual. Seus proponentes só não obtiveram inteira satisfação porque, entre outros pontos, consideram excessivamente longos os períodos de transição acordados aos países em desenvolvimento para conformarem-se a determinadas obrigaçóes (dez anos, por exemplo, no caso de extensão de proteção patentária a produtos farmacêuticos e químicos para agricultura).

Não tendo sido demandeur da extensão da cobertura do Gatt à área de propriedade intelectual, especialmente porque via com preocupação a possibilidade de que um texto de acordo sobre a matéria se tornasse um obstáculo à sua capacitação tecnológica e conduzisse à maior centralização dessa capacitação e do conhecimento em número reduzido de países desenvolvidos, o Brasil buscou, passado o longo período de impasse que caracterizou o processo negociador, 
evitar que os resultados requeressem modificações adicionais na nossa lei e nos projetos em exame no Congresso.

\section{Entendimentos sobre Regras e Procedimentos Referentes à Solução de Controvérsias (DSU)}

O documento resultante da Rodada Uruguai fortalece substancialmente 0 sistema atual, ampliando as reformas introduzidas na Reunião Ministerial de Montreal (dezembro de 1988) de forma a incluir maior automaticidade nas decisões sobre estabelecimento, termos de referência e composição de panels, bem como na própria adoção de recomendações dos mesmospanels e do recém-criado mecanismo de apelaçáo.

Nos termos do sistema integrado previsto no DSU, os membros da WTO poderão invocar qualquer dos acordos multilaterais abrigados pela Organização como base jurídica para seus pleitos. Ainda mais importante é a reafirmação de que nenhum membro determinará unilateralmente a ocorrência de uma violação deste ou daquele acordo, ou suspenderá concessões a que têm direito uma ou mais partes, devendo, ao invés, recorrer às regras e procedimentos do DSU.

Interesses específicos dos países em desenvolvimento são levados em conta no Entendimento, o qual também prescreve regras para a solução de disputas que não envolvem a violação de obrigaçóes mas advêm da avaliação de uma parte de que vantagens a que têm direito lhe estão sendo anuladas ou reduzidas.

Luiz Felipe Palmeira Lampreia, diplomata, é ministro das Relaçóes Exteriores do Brasil.

Texto base da palestra feita pelo autor em 25 de maio de 1994, no âmbito da área de Assuntos Internacionais do IEA-USP. O texto é uma primeira aproximação de síntese dos resultados da Rodada Uruguai e concentra-se nos acordos firmados em Marraqueche, incluindo breves observações críticas sobre sua relevância ou impacto para o Brasil, e excluindo considerações acerca de decisôes ministeriais de importância secundária, bem como de temas novos (comércio e meio ambiente, cláusula social). 